\title{
Book Review: Sven Björk. Limnological Methods for Environmental Rehabilitation. The Fine Art of Restoring Aquatic Ecosystems ${ }^{(1)}$
}

\author{
D. Gerdeaux
}

This book relates the long experience of its author S. Björk and colleagues, presenting numerous cases of restoration of shallow lakes and wetlands in Sweden and all over the globe. The historical conditions that led to the degraded state of ecosystems are well described. In Sweden, the lake levels were lowered to gain fertile arable land. Agricultural activities and concentrations of populations in these areas have resulted in nutrient inputs that favored the colonization of these shallow lakes by macrophytes. Water surfaces were reduced, and even disappeared. Local authorities wanted to find clean lakes and open water favorable to present human activities, but also create biodiversity.

Lake Trummen is a good example of the successful restoration of a shallow and small lake (depth $<3 \mathrm{~m} ; 1 \mathrm{~km}^{2}$ ) started in the 70s. Substantial resources were needed (dredging). It is interesting to compare the cost of this restoration after decades of pollution, that is less than the annual cost of phosphorus removal from effluents in the wastewater treatment plant that discharges its treated water into the lake.

The example of Lake Hornborga shows the limitations of the methods when the lake area is larger and invasion by macrophytes such that there is no more open water. The photographic illustration, which is on the book's cover, shows the landscape changes throughout the 45 years of restoration work. In terms of biodiversity, especially birds, the lake was returned to a good condition at the end of the 90s (Hertzman \& Larsson, 1999). However, today, the lake is still in "unsustainable development". These two lakes are excellent examples of restoration of shallow lakes where the removal of the internal load is obviously essential. The reduction or even elimination of the external load from the entire watershed would not suffice. The book then addresses other examples which include the same concepts of restoration: lagoons (Lake of Tunis, Lagoa Rodrigo de Freitas in Brazil) and lakes (Lake Paranoia in Brazil, Lake Hangzhou in China). The question is different in the Hongyuan wetlands : how to exploit peat, keeping the option to restore the ecosystem by the end of the operation? This example is treated in a very interesting way.

This book focuses on the long experience of its author and his team. It deals mainly with shallow ecosystems where it is necessary to extract or exploit the internal load. It is well illustrated, with old Swedish maps that highlight the history of these environments and ancient human impact.

Limnologists, scientists and engineers, as well as wetland historians will read this book with interest.

Cite this article as: D. Gerdeaux, 2015. Book Review: Sven Björk. Limnological Methods for Environmental Rehabilitation. The Fine Art of Restoring Aquatic Ecosystems ${ }^{(1)}$. Knowl. Manag. Aquat. Ecosyst., 416, 11. 